\title{
Alkali pretreatments and crosslinking of lyocell fabrics
}

\author{
Avinash P. Manian (1) - Arunee Kongdee Aldred • Margit Lenninger • \\ Thomas Bechtold
}

Received: 15 December 2016/ Accepted: 22 June 2017/Published online: 26 June 2017

(C) The Author(s) 2017. This article is an open access publication

\begin{abstract}
Lyocell fabrics were pretreated with $\mathrm{NaOH}, \mathrm{KOH}$ and $\mathrm{LiOH}$ and subsequently crosslinked with three urea-formaldehyde based crosslinkers DMDHEU, DMeDHEU and DMU. The mechanical properties varied with the alkali concentration in fabrics crosslinked after pretreatment with 2-8 mol/l $\mathrm{NaOH}$ and $4 \mathrm{~mol} / \mathrm{l} \mathrm{LiOH}$. In fabrics crosslinked after pretreatment with 2-8 mol/l $\mathrm{KOH}$ and $1-3 \mathrm{~mol} / \mathrm{l}$ $\mathrm{LiOH}$, in contrast, the mechanical properties were relatively insensitive to the alkali concentration. The difference in effects is attributed to the alkali influence on the accessibility of crosslinker in fiber structures. The $\mathrm{NaOH}$ and $4 \mathrm{~mol} / \mathrm{l} \mathrm{LiOH}$ pretreatments increase the accessibility of crosslinker but the $\mathrm{KOH}$ and 1-3 mol/l $\mathrm{LiOH}$ pretreatments do not appear to change accessibilities to the same extent. The results underscore the importance of alkali choice and process control in the pretreatments of lyocell. Both $\mathrm{NaOH}$ and $\mathrm{KOH}$ may be used to good effect. However,
\end{abstract}

Electronic supplementary material The online version of this article (doi:10.1007/s10570-017-1384-9) contains supplementary material, which is available to authorized users.

A. P. Manian $(\bowtie) \cdot$ M. Lenninger · T. Bechtold Research Institute of Textile Chemistry/Physics, University of Innsbruck, Hoechsterstrasse 73, 6850 Dornbirn, Austria

e-mail: avinash.manian@uibk.ac.at

A. K. Aldred

Department of Chemistry, Faculty of Science, Maejo

University, Chiang Mai 50290, Thailand lyocell is more sensitive to changes of alkali concentration in $\mathrm{NaOH}$ treatments as compared to $\mathrm{KOH}$ pretreatments. Thus, the use of $\mathrm{NaOH}$ in pretreatments of lyocell will require a greater degree of monitoring and control of alkali concentrations as compared to when $\mathrm{KOH}$ is used.

Keywords Lyocell $\cdot$ Crosslinking $\cdot$ Alkali pretreatment

\section{Introduction}

Lyocell is a regenerated cellulosic fiber that is manufactured from wood pulp dissolved in $\mathrm{N}$ methyl-morpholine- $N$-oxide. The fibers exhibit high swelling in water (Bredereck and Hermanutz 2005), and due to that, woven fabrics made of the fiber are susceptible to the formation of permanent crease marks when processed in rope form (Burrow 1998). The fiber swelling in water causes the yarns to swell and push up against each other. If the fabric is folded, the swelling stress exerted on the yarns curved around folds causes them to pull past their original positions at interlacement points, and creases are formed. Such yarn displacements cannot be reset, and hence the formed creases are permanent.

If woven fabrics are treated with alkali in open-width form before wet processing, it prevents the formation of such creases (Burrow 1998; Taylor 2015). In alkali, the 
levels of fiber/yarn swelling are far greater than with water, and that increases the yarn crimp. The crimp is retained even as the yarns de-swell when the alkali is washed off, and thus larger spaces are created between yarns at interlacement points. Now when the fabric is wetted with water, as the yarn swelling does not reach the same level as with alkali, and as the inter-yarn spaces are greater, the yarns are not pushed up against each other. It prevents the stress-induced displacement of yarns, and thus creases are not formed.

The swelling of cellulosics in alkali can change their supramolecular structure, viz., the crystallinity, porosity and accessibility, and therefore alter their sorption abilities and reactivity (Rojo et al. 2013; Xu et al. 2017). As a result, the alkali pretreatment step has the potential to influence the results of subsequent chemical processing of fabrics. A common step in cellulosic fabric processing is a treatment with crosslinker to enhance their wrinkle resistance, which is often referred to as the "durable press" or "easy care" finishing. Thus, it was of interest to determine if alkali pretreatments of lyocell exerted any influence on its subsequent crosslinking.

The alkalis commonly used in commercial-scale pretreatments of lyocell are $\mathrm{NaOH}(120 \mathrm{~g} / \mathrm{l})$ and $\mathrm{KOH}$ $(250 \mathrm{~g} / \mathrm{l})$. We examined their effects on later crosslinking with a widely used agent, dimethyloldihydroxyethylene urea (DMDHEU) (Manian et al. 2006, 2008). Fabric pieces crosslinked after alkali pretreatment exhibited lower tensile strength, lower abrasion resistance and lower crease recovery as compared to pieces crosslinked without pretreatment, although all pieces were treated with the same crosslinker formulation and all exhibited the same crosslinker content. The differences between the results from no pretreatment and $\mathrm{KOH}$ pretreatment were small, but the differences with $\mathrm{NaOH}$ pretreatment were larger. Furthermore, the $\mathrm{NaOH}$ pretreatment appeared to have changed the pore size distribution in fibers, and the distribution of DMDHEU through fibers in the pieces crosslinked after $\mathrm{NaOH}$ pretreatment was different as compared to the non-pretreated and $\mathrm{KOH}$-pretreated pieces.

To further explore these differences, the investigation was expanded to include three alkali types: $\mathrm{NaOH}$, $\mathrm{KOH}$ and $\mathrm{LiOH}$; over a wider range of concentrations: 2-8 mol/l of $\mathrm{KOH}$ and $\mathrm{NaOH}$, and $1-4 \mathrm{~mol} / \mathrm{l}$ of $\mathrm{LiOH}$; and three crosslinkers: DMDHEU, dimethyldihydroxyethylene urea (DMeDHEU) and dimethyl urea
(DMU). The maximum solubility of $\mathrm{LiOH}$ in water is about $5 \mathrm{~mol} / \mathrm{l}$ at ambient temperature, and hence its concentration range was smaller. It is not commonly used in fabric pretreatments but $\mathrm{LiOH}$ is known to influence lyocell structure such as the porosity and fibrillation propensity (Öztürk et al. 2011; Zhang et al. 2005), and hence was included in this work to better understand the effect of alkali type.

A subset of the work, viz. the effect of $\mathrm{NaOH}$ pretreatments on crosslinking with the three agents, has been reported on previously (Kongdee et al. 2010). Here, we present the remainder of the results. In the main part of the paper, we discuss the effects of pretreatments with $\mathrm{NaOH}, \mathrm{KOH}$ and $\mathrm{LiOH}$ on crosslinking with DMDHEU. In the supplementary section (Tables S1-S2 and Figures S1-S5), we show the pretreatment effects on crosslinking with DMeDHEU and DMU.

\section{Experimental materials and methods}

\section{Materials}

A $100 \%$ lyocell, 1/1 plain-woven fabric, of $138 \mathrm{~g} / \mathrm{m}^{2}$ basis weight, with 36 ends and 26 picks per centimeter comprised of 20-tex yarns was kindly supplied by Lenzing AG (Austria) and was used in the work. The crosslinking agents (see Table 1) and the wetting agent (Kieralon Jet B Conc.) were commercial products kindly provided by BASF AG (Ludwigshafen, Germany). The alkalis, crosslinking catalyst $\left(\mathrm{MgCl}_{2-}\right.$ $7 \mathrm{H}_{2} \mathrm{O}$ ), acetic acid, and sodium bicarbonate, were all analytical grade reagents, and the solutions were all formulated in deionized water.

\section{Treatments}

The alkali pretreatments were performed on fabric pieces of dimensions $30 \mathrm{~cm} \times 35 \mathrm{~cm}$ with a padbatch method. The pieces were padded through the alkali solutions at $1.0 \mathrm{~m} / \mathrm{min}$ with a nip pressure of 1 bar, rolled around glass rods, enveloped in plastic sheets, and stored at ambient temperature for $4 \mathrm{~h}$. They were then rinsed in running hot water for $5 \mathrm{~min}$, neutralized by immersion in 5\% acetic acid for $60 \mathrm{~min}$, rinsed again in running cold water for $5 \mathrm{~min}$, and line-dried overnight. The samples were then padded through crosslinker formulations at 
Table 1 The crosslinkers and formulations used in treatments

\begin{tabular}{llll}
\hline & DMDHEU & DMU & DMeDHEU \\
\hline Commercial product & Fixapret CP & Kaurit $\mathrm{S}$ & Fixapret NF \\
Solids content $(\% \mathrm{w} / \mathrm{w})^{\mathrm{a}}$ & ca. 75 & ca. 100 & ca. 45 \\
Concentrations used in crosslinking treatments $(\mathrm{g} / \mathrm{l})$ & & \\
Commercial product & 56 & 93.3 & 42 \\
Catalyst $\left(\mathrm{MgCl}_{2} \cdot 7 \mathrm{H}_{2} \mathrm{O}\right)$ & 16.8 & 32.7 & 12.6 \\
Wetting agent & 0.5 & 0.5 & 0.5 \\
\hline
\end{tabular}

$2.0 \mathrm{~m} / \mathrm{min}$ with a nip pressure of $2 \mathrm{bar}$, dried at $100{ }^{\circ} \mathrm{C}$ for $3 \mathrm{~min}$, and cured at $185{ }^{\circ} \mathrm{C}$ for $65 \mathrm{~s}$. To neutralize any residual acidity, the pieces were immersed in $1 \mathrm{~g} / \mathrm{l}$ sodium bicarbonate for $30 \mathrm{~min}$, rinsed in running cold water, and line-dried overnight.

The alkalis employed in the pretreatments were 2-8 $\mathrm{mol} / \mathrm{l}$ of $\mathrm{NaOH}$ and $\mathrm{KOH}$, and $1-4 \mathrm{~mol} / \mathrm{l}$ of $\mathrm{LiOH}$. A set of 24 pieces were pretreated at each alkali concentration, and the solutions were changed after every six pieces to minimize the effects of alkali depletion. The compositions of the crosslinker formulations are shown in Table 1, where the amounts of commercial products were adjusted to achieve a solids content of about $42 \mathrm{~g} / \mathrm{l}$. The catalyst and crosslinker amounts are derived from recommendations of the supplier (BASF AG). A set of six pieces from each alkali type/concentration went into each crosslinker treatment, and the liquors were changed after each set.

There were two sets of controls: (A) where the pieces were awarded no pretreatment, and (B) where the pieces were pretreated with deionized water (under the same conditions as with alkali except there was no neutralization).

Measurements

The wet pickup in padding was calculated from the mass change on padding as percentage of the initial mass. The dimensional change was measured by drawing $26 \mathrm{~cm} \times 26 \mathrm{~cm}$ benchmarks on the pieces before pretreatment and re-measuring the distance between them after. It was also determined from the change in mass per area measured on $100 \mathrm{~cm}^{2}$ discs punched from the non-pretreated and pretreated pieces.

The nitrogen content was determined on specimens from the crosslinked pieces on a Leco FP 328 nitrogen analyzer as a measure of their crosslinker content. Its distribution was determined by the method of negative staining with the dye C.I. Direct Red 81 (De Boer 1980), as described previously (Manian and Bechtold 2005). The carboxyl content was measured with the methylene blue dye sorption method (Klemm et al. 2004).

The breaking force and elongation at break was measured with an $18 \mathrm{~cm}$ gauge length at a $2 \mathrm{~cm} / \mathrm{min}$ rate of extension with the ISO 13934-1:1999 strip method. The values were then used to calculate the work of rupture, or toughness, with Eq. 1. The abrasion resistance was measured with the ISO 12947-3:1999 mass loss method after 6000 abrasion cycles under $9 \mathrm{kPa}$ pressure on a Martindale Abrasion Tester (Halifax, England). The wrinkle or crease recovery angle (CRA) was measured along the warp direction according to DIN 53890 after $30 \mathrm{~min}$ of recovery. The flexural rigidity was determined from bending lengths according to ISO 9073-7:1999. The specimens were then padded through deionized water at $2.0 \mathrm{~m} / \mathrm{min}$ through a nip pressure of 1 bar, and tested again for wet flexural rigidity.

$$
\begin{aligned}
\text { Work of rupture }(\mathrm{N} \mathrm{m})= & 0.5 \times \operatorname{force} \text { at break }(\mathrm{N}) \\
& \times \text { elongation at break }(\mathrm{m})
\end{aligned}
$$

The fabric pieces were all conditioned at $(20 \pm 2){ }^{\circ} \mathrm{C}$ and $(65 \pm 2) \%$ relative humidity for a minimum of $48 \mathrm{~h}$ before any measurements were performed on them. All comparisons were assessed with Analysis of Variance (ANOVA) and Bonferroni tests at a 0.05 level of significance with the software SPSS ${ }^{\circledR}$ (IBM Software, USA). The error bars in plots and parenthetical values in tables denote \pm 1 SD.

\section{Results}

The following results are available in Table 2 (from pretreated pieces) and III (from pretreated and 
Table 2 Results of measurements on pretreated (non-crosslinked) samples

\begin{tabular}{|c|c|c|c|c|c|c|c|c|c|}
\hline \multirow[t]{2}{*}{ Pretreatment } & \multirow{2}{*}{$\begin{array}{l}\text { Alkali } \\
\text { wet } \\
\text { pickup (\%) }\end{array}$} & \multicolumn{2}{|c|}{$\begin{array}{l}\text { Dimensional } \\
\text { change }(\%)\end{array}$} & \multirow[t]{2}{*}{$\begin{array}{l}\text { Mass/area } \\
\left(\mathrm{g} / \mathrm{m}^{2}\right)\end{array}$} & \multirow{2}{*}{$\begin{array}{l}\text { Carboxyl } \\
\text { content } \\
\left(10^{-3} \mathrm{mmol} / \mathrm{g}\right)\end{array}$} & \multirow[t]{2}{*}{$\begin{array}{l}\text { Breaking } \\
\text { force }(\mathrm{N})\end{array}$} & \multirow{2}{*}{$\begin{array}{l}\text { Elongation } \\
\text { at break } \\
(\%)\end{array}$} & \multirow{2}{*}{$\begin{array}{l}\text { Dye } \\
\text { content } \\
(\mathrm{g} / 100 \mathrm{~g})\end{array}$} & \multirow{2}{*}{$\begin{array}{l}\text { Color } \\
\text { depth } \\
\left(\mathrm{K} / \mathrm{S}_{\mathrm{Corr}}\right)\end{array}$} \\
\hline & & Warp & Fill & & & & & & \\
\hline \multicolumn{10}{|l|}{ Controls } \\
\hline A & - & - & - & $138.01(3.35)^{\mathrm{a}}$ & $6.09(0.97)$ & $726(11)$ & $15.6(0.0)$ & $0.63(0.02)$ & 8.57 (1.48) \\
\hline B & $106(3)$ & $3.5(0.6)$ & $0.3(0.5)$ & $143.78(1.53)$ & $7.49(0.52)$ & $689(10)$ & $15.0(0.6)$ & $0.96(0.01)$ & $11.04(0.86)$ \\
\hline \multicolumn{10}{|l|}{$\mathrm{NaOH}$} \\
\hline $2 \mathrm{~mol} / 1$ & $110(3)$ & $10.0(1.0)$ & $2.8(0.6)$ & $154.63(1.31)$ & $11.20(1.32)$ & $700(22)$ & 12.4 (1.6) & $1.04(0.05)$ & $11.31(0.49)$ \\
\hline $4 \mathrm{~mol} / \mathrm{l}$ & $117(4)$ & $14.6(1.3)$ & $8.7(0.3)$ & $175.96(1.75)$ & $13.80(2.27)$ & $532(40)$ & $16.3(0.6)$ & $0.91(0.08)$ & $15.35(0.76)$ \\
\hline $6 \mathrm{~mol} / \mathrm{l}$ & $119(3)$ & $19.4(1.4)$ & $10.2(0.1)$ & $187.92(3.71)$ & $12.68(0.11)$ & 489 (29) & $16.3(0.6)$ & $0.82(0.00)$ & $13.39(0.83)$ \\
\hline $8 \mathrm{~mol} / 1$ & $123(2)$ & $19.9(0.8)$ & $11.5(0.4)$ & $193.58(0.97)$ & $13.33(1.18)$ & $565(43)$ & $17.8(1.0)$ & $0.87(0.02)$ & $11.21(0.82)$ \\
\hline \multicolumn{10}{|l|}{$\mathrm{KOH}$} \\
\hline $2 \mathrm{~mol} / \mathrm{l}$ & $114(3)$ & $9.5(0.5)$ & $2.4(0.5)$ & $152.15(0.87)$ & $12.83(0.95)$ & $712(22)$ & $18.9(0.8)$ & $0.91(0.01)$ & $9.81(0.41)$ \\
\hline $4 \mathrm{~mol} / \mathrm{l}$ & $129(5)$ & $10.9(1.0)$ & $4.7(0.2)$ & $160.12(2.94)$ & $14.39(0.13)$ & $700(15)$ & $15.9(0.9)$ & $0.84(0.00)$ & $9.84(0.40)$ \\
\hline $6 \mathrm{~mol} / \mathrm{l}$ & $137(2)$ & $12.7(0.8)$ & $5.8(0.6)$ & $166.89(2.03)$ & $15.18(0.74)$ & 718 (27) & $15.6(0.7)$ & $0.92(0.04)$ & $10.90(0.56)$ \\
\hline $8 \mathrm{~mol} / \mathrm{l}$ & $141(3)$ & $14.0(0.6)$ & $6.3(0.8)$ & $167.48(0.69)$ & $14.93(0.73)$ & 698 (19) & $16.4(0.6)$ & $0.87(0.01)$ & $10.08(0.96)$ \\
\hline \multicolumn{10}{|l|}{$\mathrm{LiOH}$} \\
\hline $1 \mathrm{~mol} / \mathrm{l}$ & $110(15)$ & $5.5(2.0)$ & $2.1(1.9)$ & $150.00(1.83)$ & $4.92(0.47)$ & 730 (19) & $14.4(0.7)$ & $0.97(0.02)$ & $10.50(0.41)$ \\
\hline $2 \mathrm{~mol} / \mathrm{l}$ & $109(2)$ & $9.9(0.5)$ & $2.6(1.1)$ & $155.87(1.05)$ & $4.44(0.00)$ & $723(22)$ & $16.5(0.8)$ & $1.07(0.00)$ & $11.90(0.76)$ \\
\hline $3 \mathrm{~mol} / 1$ & $115(2)$ & $6.3(0.6)$ & $2.8(0.3)$ & $149.79(0.94)$ & $4.02(0.29)$ & $760(22)$ & $16.3(1.2)$ & $1.02(0.02)$ & $12.26(1.38)$ \\
\hline $4 \mathrm{~mol} / \mathrm{l}$ & $114(1)$ & $10.9(0.7)$ & $6.4(0.6)$ & 164.57 (1.88) & $12.33(2.15)$ & $637(31)$ & $16.3(0.6)$ & $0.96(0.05)$ & $14.62(1.34)$ \\
\hline
\end{tabular}

a Standard deviation

crosslinked pieces): wet pickup during pretreatment and crosslinker treatment, dimensional change as measured with benchmarks, mass/area, carboxyl content, force and elongation at break, and shade depth and dye content from the C.I. Direct Red 81 negative staining test.

The wet pickup in pretreatment increased with the concentration for all alkalis, and while there were no differences between $\mathrm{LiOH}$ and $\mathrm{NaOH}$, the levels with $\mathrm{KOH}$ were greater. The following effects may account for these observations: both the density of alkali solutions and the degree of alkali sorption by cellulose increase with the concentration (Hitchcock and McIlhenny 1935); and, at the same molar concentrations, the densities of $\mathrm{KOH}$ solutions are greater than those of $\mathrm{NaOH}$ and $\mathrm{LiOH}$ (Sipos et al. 2000). Both measurements of shrinkage in alkali pretreatmentthe dimensional changes and the changes of mass per area-yielded the same results. The shrinkage was greater along the warp direction than fill, and the levels increased with the alkali concentration. There were no differences between the alkalis up to $2 \mathrm{~mol} / \mathrm{l}$, but at higher concentrations the shrinkage with $\mathrm{NaOH}$ was greater than with $\mathrm{KOH}$ and $\mathrm{LiOH}$.
The carboxyl content in the pieces increased with concentration of alkali in the $\mathrm{NaOH}$ and $\mathrm{KOH}$ pretreatments. In the $\mathrm{LiOH}$ pretreatment, the carboxyl content initially decreased with alkali concentration up to $3 \mathrm{~mol} / \mathrm{l}$, but then rose up to the levels of the other two alkalis at $4 \mathrm{~mol} / \mathrm{l}$.

The wet pickup in crosslinker pretreatment was significantly greater in the controls as compared to the alkali-pretreated pieces. Among the pretreated samples, there was no difference between $\mathrm{LiOH}$ and $\mathrm{NaOH}$, but the crosslinker wet pickup was lower in the $\mathrm{KOH}$ pretreated pieces. Despite this, there were no significant differences of crosslinker content (as determined with the nitrogen content) between the control and pretreated pieces. One exception was a marginally greater crosslinker content in the samples pretreated with $\mathrm{NaOH}$ as compared to $\mathrm{KOH}$ at $6 \mathrm{~mol} / \mathrm{l}$ of alkali.

The work of rupture (i.e. toughness) values calculated from the force and elongation at break are shown in Fig. 1a, $a^{\prime}$. The values were significantly lower in the crosslinked as compared to the non-crosslinked pieces. In the non-crosslinked set, there were no differences between the controls and the pieces 
pretreated with $\mathrm{LiOH}$ and $\mathrm{KOH}$, but the toughness was significantly lower in the pieces pretreated with $\mathrm{NaOH}$. In the crosslinked set, the toughness in all alkali-pretreated pieces was lower than in the controls, and the toughness in the $\mathrm{KOH}$ pretreated pieces was greater than in the $\mathrm{LiOH}$ and $\mathrm{NaOH}$ pretreated pieces. The following order was observed in reduction of toughness on crosslinking: controls $<\mathrm{KOH}<\mathrm{NaOH}<\mathrm{LiOH}$.

The mass loss in abrasion resistance tests are shown in Fig. 1b, $b^{\prime}$. The mass loss in the non-crosslinked pieces was low and in the range of $1.5-5.3 \%$. The mass loss was generally much higher in the crosslinked pieces, and the levels varied widely with the alkali type and concentration in the pretreatment. For example, the lowest mass loss in the crosslinked set (of $3.1 \pm 0.5 \%$ ) was observed in the pieces pretreated with $4 \mathrm{~mol} / \mathrm{l} \mathrm{NaOH}$, and the highest mass loss (of $29.8 \pm 3.8 \%$ ) was observed in the pieces pretreated with $1 \mathrm{~mol} / \mathrm{l} \mathrm{LiOH}$.

The crease recovery angles (CRA) after $30 \mathrm{~min}$ of recovery are shown in Fig. 1c, $c^{\prime}$. As expected, the crosslinked pieces exhibited greater crease recovery than the non-crosslinked pieces. In both sets, the crease recovery was greater in the controls as compared to the alkali-pretreated pieces. In the $\mathrm{KOH}$ pretreatments, the crease recovery decreased gradually with alkali concentration. In the $\mathrm{NaOH}$ pretreatments, the values fell sharply as the alkali concentration rose from 2 to $4 \mathrm{~mol} / \mathrm{l}$, and then increased again when the alkali concentration rose further to 6 and $8 \mathrm{~mol} / \mathrm{l}$. The pieces pretreated with $\mathrm{LiOH}$ also showed a reduction of crease recovery in the range of 2-4 mol/l alkali.

The percent improvement in crease recovery on crosslinking was highest in the pieces pretreated with $4 \mathrm{~mol} / \mathrm{l} \mathrm{NaOH}$ and $\mathrm{LiOH}$ (of 51-55\%), followed by the pieces pretreated with 6 and $8 \mathrm{~mol} / \mathrm{l} \mathrm{NaOH}$ (of $39-41 \%$ ), and then by the pieces pretreated with 2-8 $\mathrm{mol} / \mathrm{l} \mathrm{KOH}$ and $1-3 \mathrm{~mol} / \mathrm{l} \mathrm{LiOH}$ (of $17-21 \%$ ). The control pieces showed a crease recovery improvement of only $7-13 \%$ on crosslinking.

The results of flexural rigidity measurements in the conditioned state are shown in Fig. 2. In the noncrosslinked set, the controls exhibited lower rigidity as compared to the alkali-pretreated pieces, especially those pretreated with 4-8 mol/l alkali; and, the rigidity was greater in the pieces pretreated with $\mathrm{NaOH}$ as compared to $\mathrm{LiOH}$ and $\mathrm{KOH}$. In the crosslinked set, the rigidity was similar in the controls and in the pieces pretreated with $\mathrm{KOH}$ and $\mathrm{LiOH}$, but greater in the pieces pretreated with $\mathrm{NaOH}$. In both the noncrosslinked and crosslinked sets, the pieces pretreated with $4 \mathrm{~mol} / \mathrm{l} \mathrm{NaOH}$ and $\mathrm{LiOH}$ exhibited significantly greater rigidity than all other pieces. The crosslinked rigidity was greater than the non-crosslinked rigidity in the controls and in the pieces pretreated with up to $2 \mathrm{~mol} / \mathrm{l}$ alkali, but in pieces pretreated with alkali at concentrations of $4 \mathrm{~mol} / \mathrm{l}$ and higher, the non-crosslinked rigidity was greater.

The results of wet flexural rigidity measurements are shown in Fig. 3. In the non-crosslinked set, the controls exhibited greater rigidity than the alkalipretreated pieces. In the crosslinked set, the rigidity was generally similar in the controls and the pieces pretreated with $\mathrm{LiOH}$ and $\mathrm{KOH}$, but the rigidity of the $\mathrm{NaOH}$-pretreated pieces were higher. Peak rigidity in the pieces pretreated with $4 \mathrm{~mol} / \mathrm{l}$ of $\mathrm{NaOH}$ and $\mathrm{LiOH}$ were observed also in all the wet rigidity measurements. In contrast to the conditioned-state measurements, the non-crosslinked rigidity was higher than the crosslinked rigidity in the controls and in the pieces pretreated with up to $2 \mathrm{~mol} / \mathrm{l}$ alkali, and the crosslinked rigidity was higher in the pieces pretreated with alkali at concentrations of $4 \mathrm{~mol} / \mathrm{l}$ and higher.

The ratios of the wet rigidity to the corresponding conditioned-state rigidity are shown in Fig. 4. In the non-crosslinked set, the ratios were much higher in the controls as compared to the alkali-pretreated pieces, and there were no significant differences between the alkali types. In the crosslinked set, the differences between the controls and the alkali-pretreated samples were smaller, and the ratios in the $\mathrm{KOH}$-pretreated pieces were lower than in the pieces pretreated with $\mathrm{NaOH}$ and $\mathrm{LiOH}$.

The principle of the negative staining test is that in crosslinked cellulosics, the Direct Red 81 dye content is inversely proportional to the crosslinker content; and for the same dye content, the color depth varies with crosslinker distribution (De Boer 1980; Rowland et al. 1983). A low color depth indicates a greater surface presence of crosslinker and a high color depth indicates a low surface presence of crosslinker. The dye contents and the corresponding color depths were both lower in the crosslinked as compared to the noncrosslinked pieces (see Tables 2, 3), but the ratios of color depth-to-dye content were remarkably similar (see Fig. 5). Among the pieces pretreated with 4 and 
Fig. 1 The work of rupture $\left(\mathbf{a}, \mathbf{a}^{\prime}\right)$, abrasion mass loss $\left(\mathbf{b}, \mathbf{b}^{\prime}\right)$, and crease recovery angle $\left(\mathbf{c}, \mathbf{c}^{\prime}\right)$ in the controls (open circle), $\mathrm{NaOH}$ pretreated (diamond), $\mathrm{KOH}-$ pretreated (inverted triangle) and LiOHpretreated (triangle) pieces. The values from the controls are shown at the arbitrary alkali concentrations of $0.25 \mathrm{~mol} / \mathrm{l}$ (control A) and $0.5 \mathrm{~mol} / \mathrm{l}$ (control B). The plots in the left column $(\mathbf{a}, \mathbf{b}$, c) show values from the noncrosslinked pieces and those in the right column $\left(\mathbf{a}^{\prime}, \mathbf{b}^{\prime}\right.$, $\mathbf{c}^{\prime}$ ) from the pieces crosslinked with DMDHEU
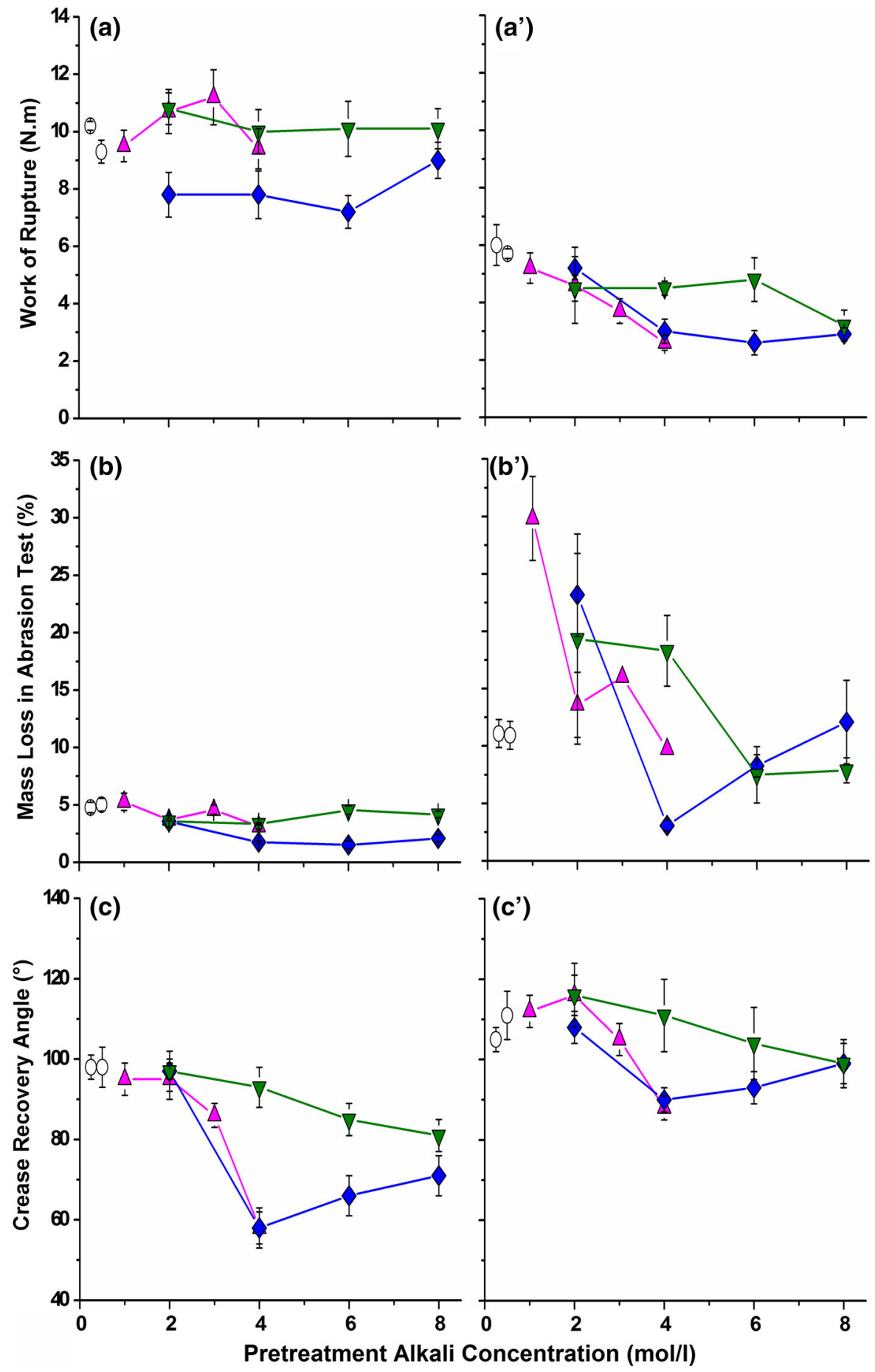

$6 \mathrm{~mol} / \mathrm{l} \mathrm{NaOH}$ and $4 \mathrm{~mol} / \mathrm{l} \mathrm{LiOH}$, the values were on average $16.1 \pm 0.9$ in the non-crosslinked set and $16.7 \pm 1.5$ in the crosslinked set. Among all other

alkali-pretreated pieces and the controls, the values were on average $11.7 \pm 0.9$ in the non-crosslinked set and $10.5 \pm 1.2$ in the crosslinked set. 


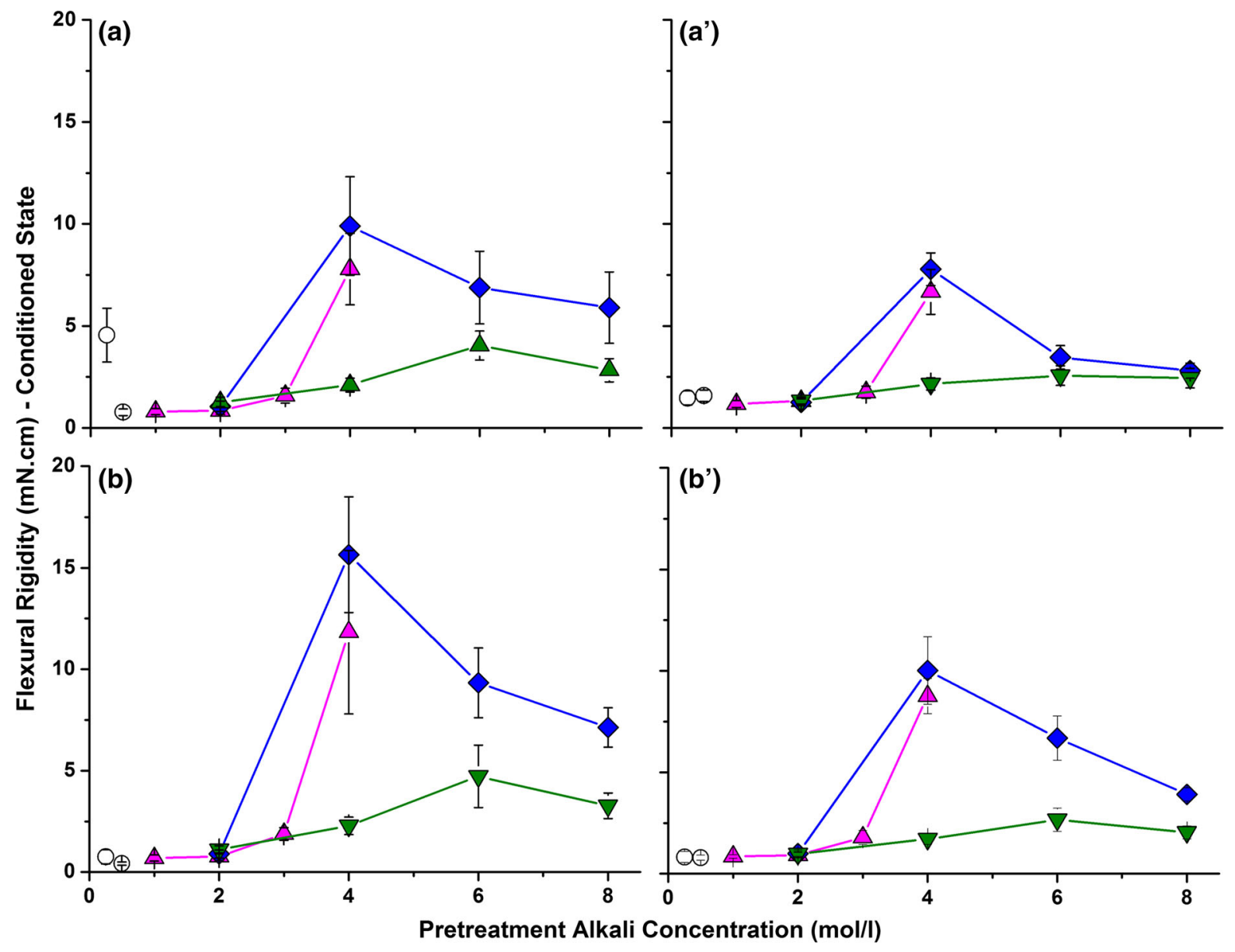

Fig. 2 The flexural rigidity measured in the conditioned state along the warp $\left(\mathbf{a}, \mathbf{a}^{\prime}\right)$ and fill $\left(\mathbf{b}, \mathbf{b}^{\prime}\right)$ directions in the controls (open circle), $\mathrm{NaOH}-$ pretreated (diamond), $\mathrm{KOH}-$ pretreated (inverted triangle) and $\mathrm{LiOH}$-pretreated (triangle) pieces. The values from the controls are shown at the arbitrary alkali

\section{Discussion}

A high flexural rigidity in fabrics results from reduced mobility of yarns past one another at crossover points, and it is accompanied by low crease recovery and poor abrasion resistance (Reeves et al. 1967; Grant et al. 1968, 1973). In the non-crosslinked set, the pieces pretreated with $4 \mathrm{~mol} / \mathrm{l} \mathrm{NaOH}$ and $\mathrm{LiOH}$ exhibited high rigidity and low crease recovery as compared to the controls, but the abrasion resistance did not differ. Therefore, the high rigidity is attributed to a temporary "setting" that is known to occur in lyocell fabrics after alkali pretreatments, which dissipates when the fabric is worked on in subsequent processing and handling. concentrations of $0.25 \mathrm{~mol} / \mathrm{l}$ (control A) and $0.5 \mathrm{~mol} / \mathrm{l}$ (control B). The plots in the left column $(\mathbf{a}, \mathbf{b})$ show values from the noncrosslinked pieces and those in the right column $\left(\mathbf{a}^{\prime}, \mathbf{b}^{\prime}\right)$ from the pieces crosslinked with DMDHEU

A rise in carboxyl content of cellulosics after alkali treatments, which was observed in the pieces pretreated with $\mathrm{NaOH}$ and $\mathrm{KOH}$ and to some degree with $\mathrm{LiOH}$, is an indicator of oxidation. But it appears that the degree of oxidation did not reach detrimental levels as there were generally no differences of strength between the controls and the alkali-pretreated pieces in the non-crosslinked set. Both exhibited the same level of abrasion resistance and, apart from the pieces pretreated with 4 and $6 \mathrm{~mol} / \mathrm{l} \mathrm{NaOH}$, the toughness levels did not differ between the controls and the alkali-pretreated pieces.

Crosslinking treatments can reduce the strength cellulosics for two primary reasons: the introduction of crosslinks leads to reduced stress dissipation in 


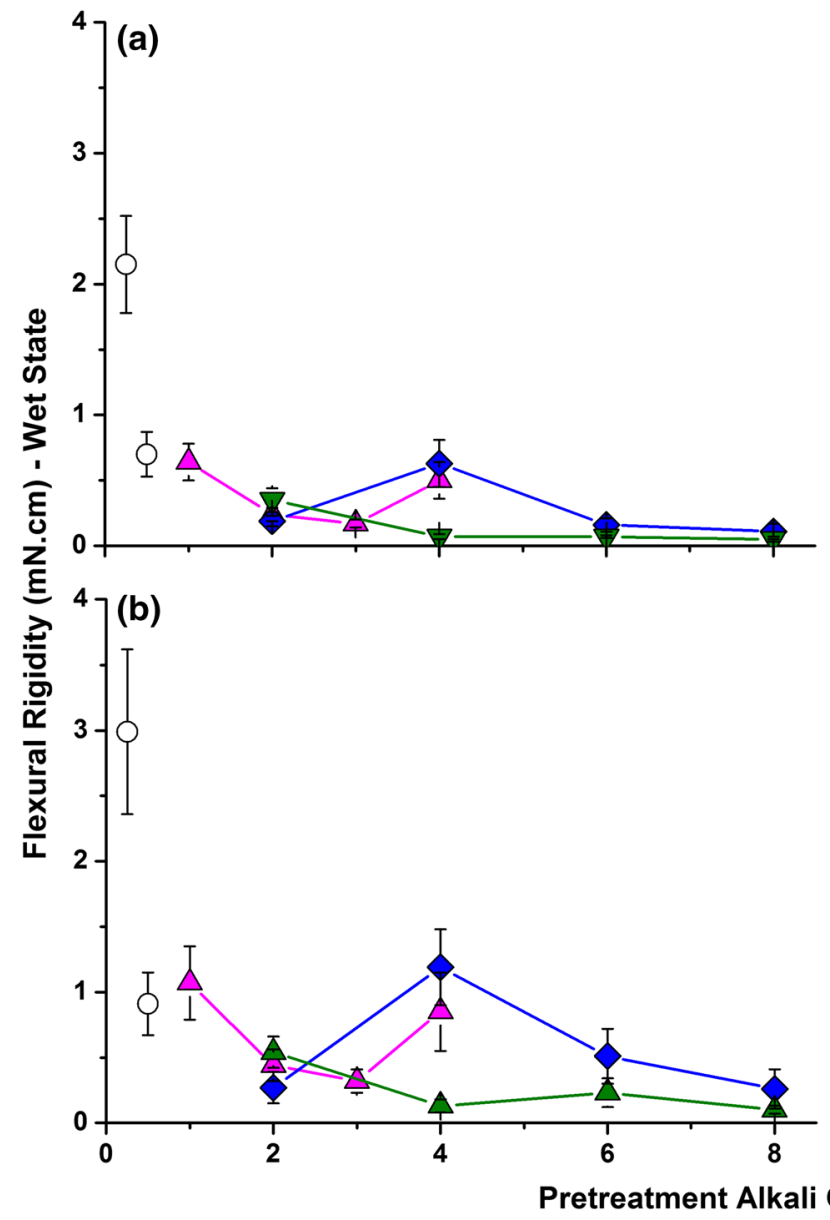

Fig. 3 The flexural rigidity measured in the wet state along the warp $\left(\mathbf{a}, \mathbf{a}^{\prime}\right)$ and fill $\left(\mathbf{b}, \mathbf{b}^{\prime}\right)$ directions in the controls (open circle), $\mathrm{NaOH}$-pretreated (diamond), $\mathrm{KOH}$-pretreated (inverted triangle) and $\mathrm{LiOH}$-pretreated (triangle) pieces. The values from the control are shown at the arbitrary alkali concentrations

fibers (embrittlement), and there is molecular degradation due to hydrolysis by catalyst (Wakelyn et al. 1998). The former is proportional to the crosslinker content in substrates, while the latter is a function of the catalyst amount in formulations and the curing conditions. The distribution of crosslinks within fiber structures also has an influence. For the same crosslinker content, the crease recovery is greater if there is a uniform distribution of crosslinks through the fiber bulk than if the crosslinks are localized at the fiber surface (Joarder et al. 1969; Grant et al. 1968; Bertoniere et al. 1981). But, a uniform distribution of crosslinks also tends to reduce tensile strength while preserving abrasion resistance, and a greater surface localization of crosslinks preserves the tensile strength
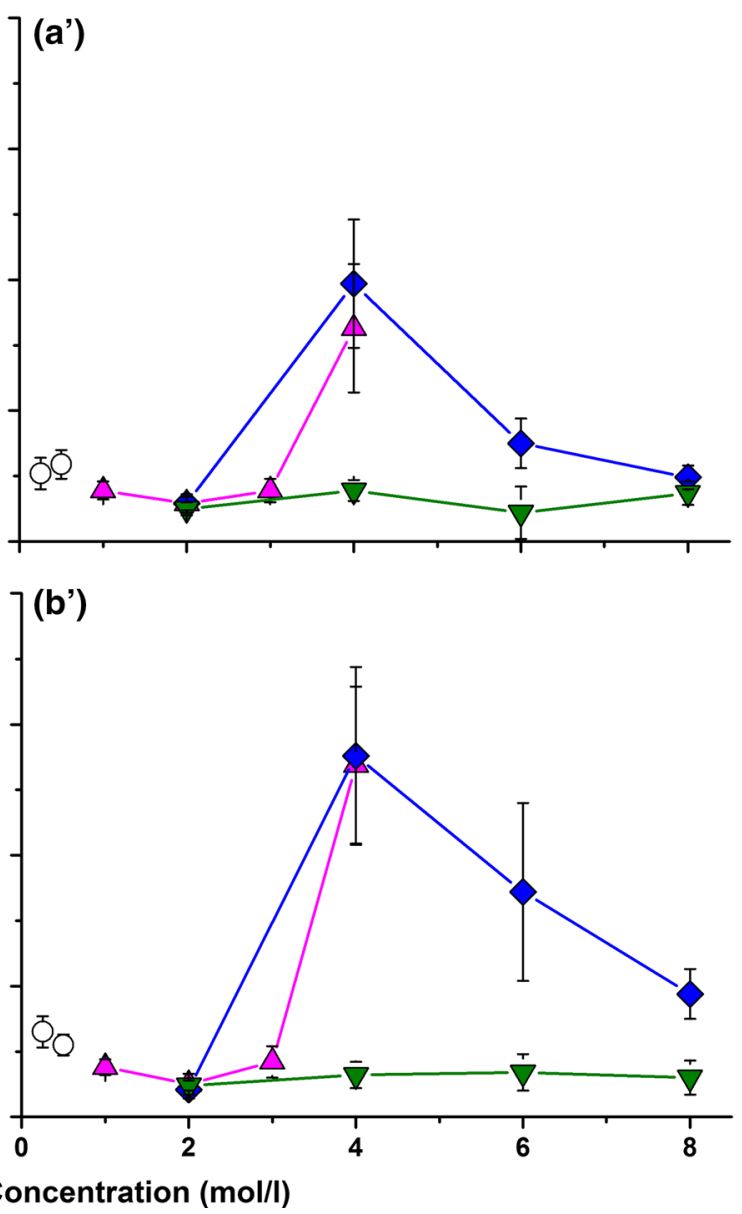

of $0.25 \mathrm{~mol} / \mathrm{l}($ control A) and $0.5 \mathrm{~mol} / \mathrm{l}$ (control B). The plots in the left column (a, b) show values from the non-crosslinked pieces and those in the right column $\left(\mathbf{a}^{\prime}, \mathbf{b}^{\prime}\right)$ from the pieces crosslinked with DMDHEU

but reduces the abrasion resistance (Bertoniere et al. 1981; Rowland et al. 1983).

As seen in the results above, the crease recovery and strength loss in the crosslinked pieces varied significantly with the alkali type and its concentration in pretreatment. All pieces were crosslinked under the same treatment conditions with identical formulations, and all exhibited very similar crosslinker contents. Thus, the variations in crease recovery and strength loss are attributed to differences of crosslinker distribution within the substrates.

In the crosslinked set, the pieces crosslinked after pretreatment with $4 \mathrm{~mol} / \mathrm{l} \mathrm{NaOH}$ and $\mathrm{LiOH}$ exhibited the highest percent improvement in crease recovery, their abrasion resistance was amongst the 
Fig. 4 The ratios of wet-toconditioned flexural rigidity along the warp $\left(\mathbf{a}, \mathbf{a}^{\prime}\right)$ and fill $\left(\mathbf{b}, \mathbf{b}^{\prime}\right)$ directions, in the controls (open circle), $\mathrm{NaOH}-$ pretreated (diamond), $\mathrm{KOH}-$ pretreated (inverted triangle) and LiOH-pretreated (triangle) pieces. The values from the controls are shown at the arbitrary alkali concentrations of $0.25 \mathrm{~mol} / \mathrm{l}$ (control A) and $0.5 \mathrm{~mol} / \mathrm{l}$ (control B). The plots in the left column $(\mathbf{a}, \mathbf{b})$ show values from the noncrosslinked pieces and those in the right column $\left(\mathbf{a}^{\prime}, \mathbf{b}^{\prime}\right)$ from the pieces crosslinked with DMDHEU. Note the different scales on the ordinate in each plot

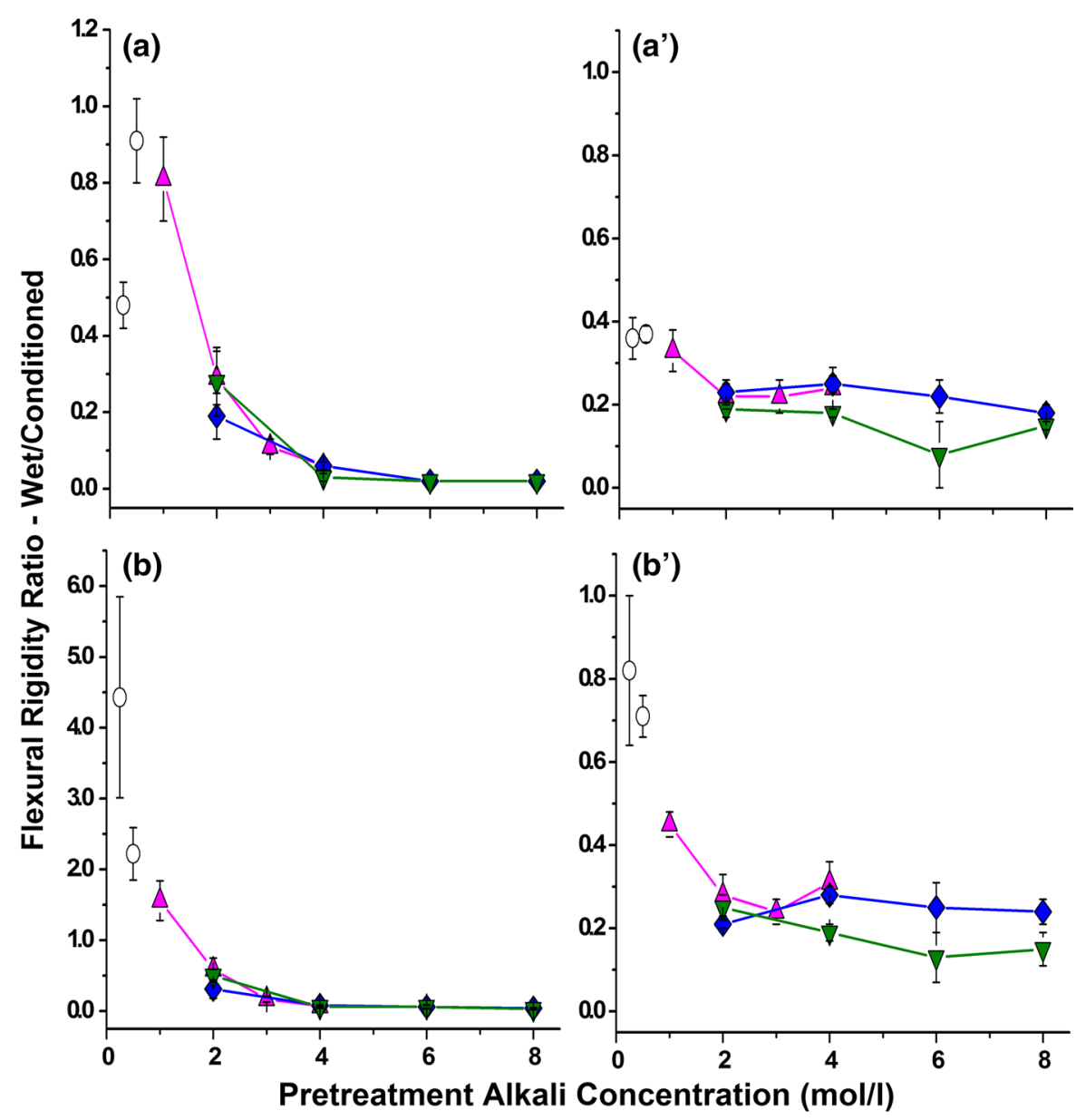

highest, and their toughness was amongst the lowest. In addition, their color depth/dye content ratios were the highest. The same combination of properties, though to lower extents than with $4 \mathrm{~mol} / \mathrm{l}$ alkali, were also observed in the pieces crosslinked after pretreatment with 6 and $8 \mathrm{~mol} / \mathrm{l} \mathrm{NaOH}$. In comparison, the pieces crosslinked after pretreatment with 1-3 mol/l $\mathrm{LiOH}$ and $2-8 \mathrm{~mol} / \mathrm{l} \mathrm{KOH}$ exhibited generally lower crease recovery improvement, lower abrasion resistance, lower color depth/dye content ratios and higher toughness.

All of these observations suggest that in the pieces crosslinked after pretreatment with $\mathrm{NaOH}$ (and $4 \mathrm{~mol} /$ $1 \mathrm{LiOH}$ ), there was a greater penetration of the crosslinker within the fiber bulk as compared to a greater surface presence in the pieces crosslinked after $\mathrm{KOH}$ and $1-3 \mathrm{~mol} / \mathrm{l} \mathrm{LiOH}$. Further evidence in support of this inference may be observed in the flexural rigidity results. The ratios of wet/conditioned rigidities in the crosslinked set were greater in the pieces pretreated with $\mathrm{NaOH}$ and $4 \mathrm{~mol} / \mathrm{l} \mathrm{LiOH}$ as compared to the pieces pretreated with $\mathrm{KOH}$ and 1-3 mol/l LiOH, which indicates that the Young's modulus was greater in the former as compared to the latter (Matsuo 1969). An improvement of the Young's modulus on crosslinking is observed with increase in the degree of crosslinker penetration in the fiber bulk (Frick et al. 1960).

The trends observed in the DMDHEU crosslinked pieces as discussed above were also observed in the pieces crosslinked with DMU and DMeDHEU (see supplementary tables S1-S2 and figures S1-S5), and hence the above discussion applies for all three crosslinkers. 
Table 3 Results of measurements on DMDHEU-crosslinked samples

\begin{tabular}{|c|c|c|c|c|c|c|}
\hline Pretreatment & $\begin{array}{l}\text { Crosslinker } \\
\text { wet pickup }(\%)\end{array}$ & $\begin{array}{l}\text { Nitrogen } \\
\text { content }(\%)\end{array}$ & $\begin{array}{l}\text { Breaking } \\
\text { force }(\mathrm{N})\end{array}$ & $\begin{array}{l}\text { Elongation } \\
\text { at break }(\%)\end{array}$ & $\begin{array}{l}\text { Dye content } \\
(\mathrm{g} / 100 \mathrm{~g})\end{array}$ & $\begin{array}{l}\text { Color depth } \\
\left(\mathrm{K} / \mathrm{S}_{\mathrm{Corr}}\right)\end{array}$ \\
\hline \multicolumn{7}{|l|}{ Controls } \\
\hline A & $79.5(0.4)^{\mathrm{a}}$ & $0.436(0.025)$ & $631(41)$ & $10.6(0.6)$ & $0.36(0.01)$ & $3.91(0.78)$ \\
\hline B & $78.6(0.9)$ & $0.434(0.013)$ & $630(19)$ & $10.0(0.0)$ & $0.34(0.03)$ & $3.17(0.44)$ \\
\hline \multicolumn{7}{|l|}{$\mathrm{NaOH}$} \\
\hline $2 \mathrm{~mol} / \mathrm{l}$ & 76.9 (1.5) & $0.449(0.003)$ & $593(41)$ & $9.8(0.5)$ & $0.27(0.04)$ & $2.84(0.35)$ \\
\hline $4 \mathrm{~mol} / \mathrm{l}$ & $73.1(1.2)$ & $0.429(0.006)$ & $361(17)$ & $9.3(0.9)$ & $0.29(0.01)$ & $5.24(0.37)$ \\
\hline $6 \mathrm{~mol} / \mathrm{l}$ & $76.8(0.5)$ & $0.459(0.013)$ & $306(22)$ & $9.4(0.9)$ & $0.25(0.04)$ & $3.80(0.61)$ \\
\hline $8 \mathrm{~mol} / \mathrm{l}$ & $77.5(0.6)$ & $0.442(0.001)$ & $366(23)$ & $8.9(0.7)$ & $0.25(0.03)$ & $2.96(0.39)$ \\
\hline \multicolumn{7}{|l|}{$\mathrm{KOH}$} \\
\hline $2 \mathrm{~mol} / \mathrm{l}$ & $73.2(2.1)$ & $0.469(0.011)$ & $523(23)$ & $9.4(0.6)$ & $0.19(0.02)$ & $2.14(0.13)$ \\
\hline $4 \mathrm{~mol} / \mathrm{l}$ & $71.0(1.5)$ & $0.433(0.011)$ & $550(31)$ & $9.1(0.5)$ & $0.27(0.03)$ & $3.04(0.33)$ \\
\hline $6 \mathrm{~mol} / \mathrm{l}$ & $70.6(1.3)$ & $0.394(0.051)$ & 549 (39) & $9.6(0.9)$ & $0.65(0.16)$ & 4.97 (1.33) \\
\hline $8 \mathrm{~mol} / \mathrm{l}$ & $70.5(0.6)$ & $0.422(0.007)$ & $450(50)$ & $7.8(0.7)$ & $0.42(0.07)$ & $4.23(0.98)$ \\
\hline \multicolumn{7}{|l|}{$\mathrm{LiOH}$} \\
\hline $1 \mathrm{~mol} / \mathrm{l}$ & $78.4(0.9)$ & $0.465(0.005)$ & $600(43)$ & $9.6(0.6)$ & $0.23(0.03)$ & $2.53(0.45)$ \\
\hline $2 \mathrm{~mol} / \mathrm{l}$ & $76.4(2.3)$ & $0.464(0.009)$ & $540(100)$ & $9.3(1.2)$ & $0.28(0.02)$ & $2.87(0.52)$ \\
\hline $3 \mathrm{~mol} / \mathrm{l}$ & $73.8(0.6)$ & $0.458(0.006)$ & 477 (36) & $8.5(0.6)$ & $0.24(0.03)$ & $2.61(0.15)$ \\
\hline $4 \mathrm{~mol} / \mathrm{l}$ & $74.1(0.9)$ & $0.446(0.003)$ & 343 (18) & $8.5(0.6)$ & $0.24(0.06)$ & $4.11(0.54)$ \\
\hline
\end{tabular}

a Standard deviation

Fig. 5 The ratio of color depth to dye content in the controls (open circle), $\mathrm{NaOH}$-pretreated (diamond), $\mathrm{KOH}$-pretreated (triangle) and $\mathrm{LiOH}-$ pretreated (triangle) pieces, from the non-crosslinked set (a) and from the DMDHEUcrosslinked set (b). The values from the control pieces are shown at the arbitrary alkali concentrations of $0.25 \mathrm{~mol} / \mathrm{l}$ (control A) and $0.5 \mathrm{~mol} / 1$ (control B)

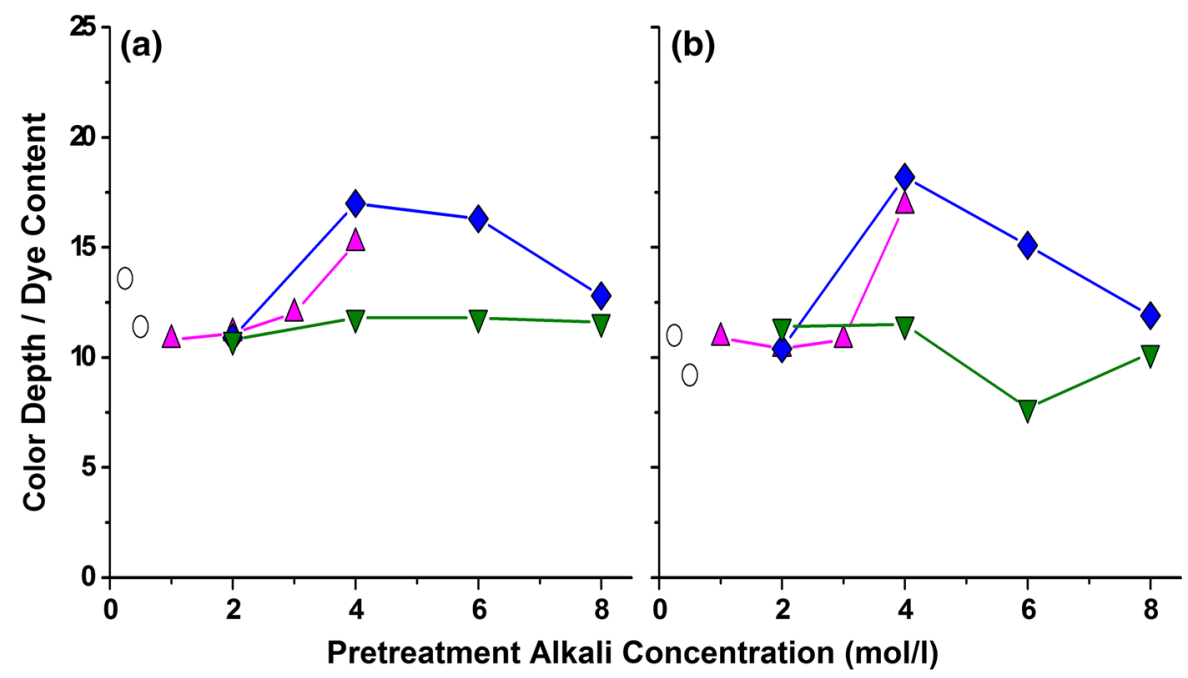

$\mathrm{LiOH}$ on the crosslinking results. In contrast, the pretreatments with $2-8 \mathrm{~mol} / \mathrm{l} \mathrm{KOH}$ and with $1-3 \mathrm{~mol} /$ $1 \mathrm{LiOH}$ did not exert a strong influence on the results of the subsequent crosslinking treatment. These results indicate that the pretreatments with $2-8 \mathrm{~mol} / \mathrm{l} \mathrm{NaOH}$ and $4 \mathrm{~mol} / \mathrm{l} \mathrm{LiOH}$ significantly alter the accessibility of crosslinker in the fibers. 
Both $\mathrm{NaOH}$ and $\mathrm{KOH}$ may be used to good effect in pretreatments to reduce the wet stiffness of lyocell fabrics, but the results indicate that greater care is required in pretreatments with $\mathrm{NaOH}$. Like all cellulosics, lyocell exhibits high affinity for alkali, and thus there is a tendency of alkali depletion from process liquors during the course of the pretreatment. Lyocell is more sensitive to the changes in concentration of $\mathrm{NaOH}$ as compared to $\mathrm{KOH}$, and thus concentration differences in pretreatments with $\mathrm{NaOH}$ may exert a greater negative impact on subsequent processing than pretreatments with $\mathrm{KOH}$. Thus, it is more important to monitor and control alkali concentrations in treatments with $\mathrm{NaOH}$ as compared to $\mathrm{KOH}$.

Acknowledgments Open access funding provided by University of Innsbruck and Medical University of Innsbruck. The authors gratefully acknowledge Lenzing AG and BASF AG for their kind donations of the fabrics and crosslinker formulations respectively. The Höhere Technische Bundeslehr- und Versuschsanstalt Dornbirn is gratefully acknowledged for the access to their facilities.

Open Access This article is distributed under the terms of the Creative Commons Attribution 4.0 International License (http:// creativecommons.org/licenses/by/4.0/), which permits unrestricted use, distribution, and reproduction in any medium, provided you give appropriate credit to the original author(s) and the source, provide a link to the Creative Commons license, and indicate if changes were made.

\section{References}

BASF AG, Technical Information Sheets (a) TI/T $5171 \mathrm{~d}$ January 1995; (b) TI/T 6073 d June 1996; (c) TI/T 7266 d February 2007. BASF AG, Ludwigshafen

Bertoniere NR, King WD, Rowland SP (1981) Reagent migration and the performance of durable-press fabrics. Text Res J 51(4):242-251. doi:10.1177/004051758105100404

Bredereck K, Hermanutz F (2005) Man-made cellulosics. Rev Prog Color Relat Top 35(1):59-75. doi:10.1111/j.14784408.2005.tb00160.x

Burrow T (1998) Recent results with lyocell ${ }^{\circledR}$ fibres in textiles. Lenzing Ber 78:37-40

De Boer JJ (1980) The determination of the degree of migration of easy-care chemicals in cotton fabrics. Text Res J 50(11):648-654. doi:10.1177/004051758005001102

Frick JG, Andrews BAK, Reid JD (1960) Effects of crosslinkage in wrinkle-resistant cotton fabrics. Text Res J 30(7):495-504. doi:10.1177/004051756003000704

Grant JN, Andrews FR, Weiss LC, Charles B, Hassenboehler J (1968) Abrasion and tensile properties of cross-linked cotton fabrics. Text Res J 38(3):217-225. doi:10.1177/ 004051756803800302
Grant JN, Hebert JJ, Andrews FR, Wadsworth JI, Orr RS (1973) Tension and resin-treatment effects on properties of scoured and mercerized cotton fibers and fabrics of different constructions. Text Res J 43(7):413-422. doi:10. 1177/004051757304300709

Hitchcock LB, McIlhenny JS (1935) Viscosity and density of pure alkaline solutions and their mixtures. Ind Eng Chem 27(4):461-466. doi:10.1021/ie50304a027

Joarder GK, Brannan MA, Rowland SP, Guthrie JD (1969) An uncatalyzed, vapor-phase cross-linking reaction of cotton cellulose with formaldehyde. Text Res J 39(1):49-54. doi:10.1177/004051756903900109

Klemm D, Philipp B, Heinze T, Heinze U, Wagenknecht W (2004) Appendix to volume 1: experimental protocols for the analysis of cellulose. In: Comprehensive cellulose chemistry. Wiley-VCH Verlag GmbH \& Co. KGaA, pp 223-251. doi:10.1002/3527601929.app1

Kongdee A, Manian AP, Lenninger M, Schlangen J, Bechtold T (2010) Alkali pretreatment and resin finishing of lyocell: effect of sodium hydroxide pretreatments. J Appl Polym Sci 115(5):2898-2910. doi:10.1002/app.31367

Manian AP, Bechtold T (2005) Drying rates in resin treatment of lyocell fabrics. Text Res J 75(3):258-264. doi:10.1177/ 004051750507500312

Manian AP, Rous MA, Schuster KC, Bechtold T (2006) The influence of alkali pretreatments in lyocell resin finishing-resin distribution and mechanical properties. J Appl Polym Sci 100(5):3596-3601. doi:10.1002/app.23038

Manian AP, Abu-Rous M, Lenninger M, Roeder T, Schuster KC, Bechtold T (2008) The influence of alkali pretreatments in lyocell resin finishing-fiber structure. Carbohydr Polym 71(4):664-671. doi:10.1016/j.carbpol.2007.07.020

Matsuo T (1969) Bending of woven fabrics. J Text Mach Soc Jpn 15(1):19-33

Öztürk HB, MacNaughtan B, Mitchell JR, Bechtold T (2011) What does $\mathrm{LiOH}$ treatment offer for lyocell fibers? Investigation of structural changes. Ind Eng Chem Res 50(15):9087-9094. doi:10.1021/ie1015624

Reeves WA, Hamalainen C, Mard HHS, Cooper AS (1967) Poly-set process for producing durable-press cotton goods 1. Text Res J 37(2):76-88. doi:10.1177/ 004051756703700203

Rojo E, Alonso MV, Domínguez JC, Saz-Orozco BD, Oliet M, Rodriguez F (2013) Alkali treatment of viscose cellulosic fibers from eucalyptus wood: structural, morphological, and thermal analysis. J Appl Polym Sci 130(3):2198-2204. doi:10.1002/app.39399

Rowland SP, Bertoniere NR, King WD (1983) Assessment of fabric performance versus reagent location from lick roller application of DMDHEU. Text Res J 53(3):187-196. doi: $10.1177 / 004051758305300308$

Sipos PM, Hefter G, May PM (2000) Viscosities and Densities of Highly Concentrated Aqueous $\mathrm{MOH}$ Solutions $(\mathrm{M}+=\mathrm{Na}+, \mathrm{K}+, \mathrm{Li}+, \mathrm{Cs}+,(\mathrm{CH} 3) 4 \mathrm{~N}+)$ at $25.0^{\circ} \mathrm{C}$. J Chem Eng Data 45(4):613-617. doi:10.1021/je000019h

Taylor J (2015) Controlling fibrillation-experiences of the dyeing and finishing of lyocell fibres. Color Technol 131(6):424-433. doi:10.1111/cote.12184

Wakelyn PJ, Bertoniere NR, French AD, Zeronian SH, Nevell TP, Thibodeaux DP, Blanchard EJ, Calamari TA, Triplett BA, Bragg CK, Welch CM, Timpa JD, Goynes WR Jr, 
Franklin WE, Reinhardt RM, Vigo TL (1998) Cotton fibers. In: Lewin M, Pearce EM (eds) Handbook of fiber chemistry, 2nd edn. Marcel Dekker Inc, New York, pp 577-724

Xu Y, Xu Y, Yue X (2017) Changes of hydrogen bonding and aggregation structure of cellulose fiber due to microwaveassisted alkali treatment and its impacts on the application as fluff pulp. Cellulose 24(2):967-976. doi:10.1007/ s10570-016-1147-z

Zhang W, Okubayashi S, Bechtold T (2005) Fibrillation tendency of cellulosic fibers-part 3. Effects of alkali pretreatment of lyocell fiber. Carbohyd Polym 59(2):173-179. doi:10.1016/j.carbpol.2004.09.007 